René Schmoll, Stefan Süß*

\title{
Working Anywhere, Anytime: An Experimental Investigation of Workplace Flexibility's Influence on Organizational Attraction ${ }^{* *}$
}

\begin{abstract}
Offering workplace flexibility to attract new talent has become a strategic issue for many organizations. Workplace flexibility provides employees with the autonomy to choose when and where to perform their work. Even though there is some evidence of its positive influence on organizational attraction, research that differentiates the influence of temporal and spatial flexibility is lacking, leaving their separate and joint effects largely unclear. Furthermore, whether the principle of distribution influences this relationship is also unclear. Drawing on signaling theory, we perform an experimental study that helps to clarify how workplace flexibility influences organizational attraction. We conduct a randomized vignette-based experiment $(\mathrm{N}=334)$ that manipulates temporal flexibility, spatial flexibility and equity-based distribution. The results indicate significant main effects for both dimensions of flexibility, with temporal flexibility having a stronger influence. For the combination of temporal and spatial flexibility, we found an additive effect rather than a significant interaction. The experiment did not detect any evidence for a moderating role of equity-based distribution. The paper provides contributions to research and practice. Finally, we discuss our findings with regard to limitations and make suggestions for future research.
\end{abstract}

Keywords: workplace flexibility, flexible work arrangements, organizational attraction, applicant attraction, experiment

(JEL: M50, M54, M59, C9)

\section{Introduction}

Workplace flexibility has become increasingly important on the individual, organizational and socio-political level. It provides individuals with discretion over temporal and spatial flexibility in the workplace and, thus, with the control and autonomy

* René Schmoll: Chair of Business Administration, in particular Organization Studies and Human Resource Management, Heinrich-Heine University Duesseldorf, Universitätsstraße 1, 40225 Düsseldorf, E-Mail: rene.schmoll@hhu.de

Prof. Dr. Stefan Süß: Chair of Business Administration, in particular Organization Studies and Human Resource Management, Heinrich-Heine University Duesseldorf, Universitätsstraße 1, 40225 Düsseldorf, E-Mail: stefan.suess@hhu.de.

** Article submitted: December 20, 2017

Article accepted: November 15, 2018

mrev, 30 (1) 2019, $40-62$ 
they need to address the demands of both work and family (Hill et al., 2010; Allen et al., 2013). From the organizational perspective, workplace flexibility can enable companies to adapt to rapidly changing demands in the modern world of work, such as accelerating digitization and expanding customer expectations (Gerdenitsch et al., 2015; Kossek \& Thompson, 2016). Workplace flexibility is also reflected in the socio-political discourse (e.g., Bundesministerium für Arbeit und Soziales, 2016, 2017, for Germany) and is increasingly manifested in national laws (e.g., The Stationery Office, 2014, for Great Britain; Ministerie van Sociale Zaken en Werkgelegenheid, 2016, for the Netherlands).

Since the 1970s, research has dealt with temporal (e.g., Evans, 1973) and spatial flexibility (e.g., Nilles, 1975) in the workplace. However, the rapidly accelerating digitization has revolutionized workplace flexibility (e.g., Messenger \& Gschwind, 2016). Modern information and communication technologies (ICT), such as smartphones and tablet computers, enable work to shift beyond traditional temporal and spatial boundaries (Nansen et al., 2010; Diaz et al., 2012). Nowadays, many work tasks can be done at any time and from any place (Blount, 2015; Messenger \& Gschwind, 2016). In addition, the need for flexibility is reinforced by changes in individual and social values. While standardized working days that individuals cannot vary in duration or location (e.g., "9-to-5 workday") have been the norm for a long time (Beers, 2000), today's employees increasingly demand individualized working conditions that correspond to the demands of their personal lives (Rousseau et al., 2006; Guest \& Rodrigues, 2015). Moreover, the "war for talent" has become a key challenge for organizations (Pfeffer, 2001; Beechler \& Woodward, 2009).

As a consequence, organizations seek to improve their organizational attraction (Lievens et al., 2001; Rode \& Süß, 2015), or more precisely, "the envisioned benefits that a potential employee sees in working for a specific organization" (Berthon et al., 2005, p. 156). Organizational attraction affects potential applicants' decision whether they will apply for a job and what they expect from the company if they accept one (Aiman-Smith et al., 2001; Cable \& Turban, 2001). Potential applicants judge organizational attraction on the basis of numerous criteria. In addition to monetary compensation, non-monetary factors like work conditions and a balance between work and private life have become very important to applicants (Boswell et al., 2003). In this context also implementing workplace flexibility has become an essential tool in attracting talent (Hill et al., 2008; Possenriede \& Plantenga, 2014).

Despite the prevalence of workplace flexibility as a tool for attracting talent, it is not clear if it actually influences organizational attraction. While various practice-oriented publications proclaim the positive influence of workplace flexibility on organizational attraction (e.g., Winiger, 2011; Bundesministerium für Arbeit und Soziales, 2016), there is a lack of empirical research on the topic. The few scientific publications often focus on the effects of either temporal or spatial flexibility, not 
both. For instance, there is some evidence for the positive impact of home-based teleworking (Rau \& Hyland, 2002) and work-time models (Nadler et al., 2010) on organizational attraction. Overall, there is a shortage of empirical work that deals with the different combinations of temporal and spatial flexibility (Hill et al., 2010; Allen et al., 2013; Allen et al., 2015; Thompson et al., 2015). This is problematic because in practice temporal and spatial flexibility often occur in several combinations (Allen et al., 2013; Kossek et al., 2014). For example, Parent-Thirion et al. (2016) show that almost three-quarters (72\%) of employees across the EU who are granted spatial flexibility are also given temporal flexibility.

In their meta-analysis Allen et al. (2013) found that a major dilemma in the research on flexibility is a lack of clear and consistent differentiation between temporal and spatial flexibility. With this in mind, we differentiate the two types of flexibility instead of aggregating them into a single construct. This is important as workplace flexibility often refers to the interrelationship of temporal and spatial flexibility (Handley et al., 2017). The two types of flexibility are not interchangeable and aggregating them into a single construct may mask differential effects (Allen et al., 2013). We argue that only analyzing both flexibility types in one controlled setting makes it possible to shed light on their unbiased impact on organizational attraction. In making a clear differentiation we contribute to the workplace flexibility literature by providing a more nuanced and precise understanding of their divergent effects and their potential relationship. In doing so, we also contribute to the recruitment literature by clarifying the aspects of flexibility that are more or less beneficial to organizational attraction. In contrast to other studies (e.g., Rau \& Hyland, 2002; Thompson et al., 2015), we also provide information about the influence of "anywhere working" on organizational attraction. In addition, we enrich the literature on signaling theory by addressing the issue of signal consistency (e.g., Gao et al., 2008; Connelly et al., 2011). A clear differentiation between temporal and spatial flexibility makes it possible to analyze if inconsistent signals regarding flexibility may unsettle potential applicants and damage recruitment outcomes.

Furthermore, the extent to which an equity-based vs. an equality-based distribution of workplace flexibility influences organizational attraction also remains unclear, which is surprising, as the literature revealed this as a primary tension in the context of workplace flexibility (e.g, Swanberg, 2005; Putnam et al., 2014). Organizations distribute workplace flexibility inconsistently. While some organizations proactively advertise that all of their employees are able to enjoy workplace flexibility (Bundesministerium für Arbeit und Soziales, 2015), others use it as a reward for high performance (Swanberg, 2005). However, there is no research on the distribution of workplace flexibility and its impact on employer attractiveness. The present study seeks to address this deficit. 
Against this background, this paper aims to analyze the differential influence of workplace flexibility on organizational attraction and to explore the moderating role of equity-based distribution of workplace flexibility.

\section{Theoretical Background and Development of Hypotheses}

\section{Deconstructing Workplace Flexibility}

Despite its widespread use for decades in the academic and the applied literature, many researchers note that workplace flexibility is still a poorly understood and ambiguously defined construct (Hill et al., 2008; Allen et al., 2013; Kossek \& Thompson, 2016). Hill et al. (2008, p. 149) define workplace flexibility as "the ability of workers to make choices influencing when, where, and for how long they engage in work-related tasks." Workplace flexibility can be provided to employees by offering them flexible work arrangements (FWA), which are defined as work options that permit flexibility in terms of "where" and/or "when" work is performed (Allen et al., 2013). The discourse also often takes place under the label of new ways of working (NWW) (Brummelhuis et al., 2012; Demerouti et al., 2014; Handley et al., 2017). In all such discourse, temporal and spatial flexibility (time and location of work) are the main dimensions of flexibility in the workplace (Hill et al., 2010; Allen et al., 2013; Gärtner et al., 2016).

As discussed by Allen et al. (2009, 2013), there are some flexible working arrangements that only allow spatial but no temporal flexibility, or vice versa. For instance, individuals may be able to work away from the office but have to follow a rigid schedule. It is also conceivable that individuals receive schedule flexibility but are required to complete all work on-site. But it is most likely that the combination of both flexibility types occurs (Parent-Thirion et al., 2016). We take a look at the highest degree of both flexibility dimensions, meaning that employees can choose when and where they perform their work, without being restricted in terms of time or location. Although not all companies can provide this high degree of flexibility to their employees (e.g., due to production requirements or customer expectations), it already takes place in practice (e.g., Microsoft, 2014; Bundesministerium für Arbeit und Soziales, 2015).

\section{The Signaling Function of Workplace Flexibility}

Signaling theory (Spence, 1973) proposes that there is an asymmetric distribution of information between two parties in the market. For example, in the early stages of the recruitment process, applicants have incomplete information about organizations and their work conditions, which makes it difficult for them to know what it would be like to be a company's employee (Turban, 2001). Thus, they rely on signals that they receive from the organization in order to make inferences about working conditions and other organizational characteristics (Jones et al., 2014). Organizations (the senders) send out such signals to reduce these information asym- 
metries and thereby position themselves as attractive employers. Potential applicants (the receivers) interpret the signals, in order to draw conclusions about the organizations' work conditions and values (Connelly et al., 2011) and evaluate the attractiveness of an employer (Baum et al., 2016). Usually, applicants are especially likely to respond favorably to employee-centered values (Perry-Smith \& Blum, 2000).

Drawing on signaling theory (Spence, 1973) we argue that offering workplace flexibility has positive effects on organizational attraction. On the one hand, organizations that offer temporal and spatial flexibility may signal that they care about their employees' well-being (Eisenberger et al., 1990; Lambert, 2000; Masuda et al., 2012). On the other hand, workplace flexibility may signal that organizations offer a high level of autonomy and self-control to their employees, thereby allowing them to maximize their rewards (e.g., managing work and family roles).

Autonomy is a fundamental psychological need (Ryan \& Deci, 2000), a key element of job quality (Clark, 2005), and a key resource for meeting work and family demands (Allen et al., 2013; Kossek \& Thompson, 2016). By signaling that applicants can choose when and where to work, organizations address the need for autonomy and create a feeling of self-control (Gerdenitsch et al., 2015). Giving employees the ability to control their working conditions can be explained as an important mechanism in promoting individual well-being (Karasek, 1979). Offering spatial flexibility may signal trust in remote workers, because their efforts are not routinely visible to the supervisor as they would be at a central work location (Gajendran et al., 2015). Offering temporal flexibility may signal that the organization is supportive of employees personal needs (Casper \& Buffardi, 2004), e.g. by being responsive to their individual biorhythms. Following this argumentation, we propose that both temporal and spatial flexibility increases the organizational attraction of potential applicants.

Hypothesis 1a: Potential applicants perceive an organization that offers temporal flexibility as more attractive than an organization that does not offer temporal flexibility.

Hypothesis 1b: Potential applicants perceive an organization that offers spatial flexibility as more attractive than an organization that does not offer spatial flexibility.

The degree of self-control plays a central role in determining an employees' wellbeing (Karasek, 1979). The more aspects of employees' working conditions they can control themselves, the better they can handle their work demands. When organizations give their employees the choice to determine when (temporal flexibility) and where (spatial flexibility) to work, employees perceive a higher degree of self-control and autonomy than they do, if only one form of flexibility is offered. Therefore, if an organization sends information about the availability of temporal and spatial flexibility, applicants may perceive it as a signal that the organization will provide 
them with the highest level of autonomy and self-control. In contrast, receiving only one form of flexibility could be less beneficial. For instance, someone with spatial flexibility who is forced to remain chained to work "from eight to five" may perceive only little more autonomy than someone sitting in the corporate office during the same time (Allen \& Shockley, 2009). Therefore, we propose that prospective employees' perceived organizational attractiveness is greatest when both temporal and spatial flexibility is offered.

\section{Hypothesis 2: Potential applicants perceive an organization that offers both temporal and spatial flexibility as more attractive than an organization that offers only one or the other.}

\section{The Moderating Role of Equity-Based Distribution}

While some authors argue that workplace flexibility should be a right for all employees, rather than a benefit for some (e.g., Putnam et al., 2014), others plead for providing it in proportion to employees' input (e.g., Hornung et al., 2008). The latter is often explained by the fact that organizations usually have limited resources and they have to decide which employees can be granted such flexibility (Swanberg, 2005).

Research on distributive justice has analyzed various distribution rules. The rules that receive the most widespread and intense interest among organizational researchers and theorists are the equity rule and the equality rule (Meindl, 1989; Kabanoff, 1991). According to the equality rule, workplace flexibility should be given to all employees, regardless of their performance inputs, while the equity rule says that it should be distributed based on employees' inputs (Adams, 1969). The two distribution principles are in a tense relationship, as "if the requirements of one principle are met to a great extent, the requirements of the other will be met to a lesser extent" (Kabanoff, 1991, p. 421). This view also highlights the tensions of equity-based versus equality-based distribution of workplace flexibility (Putnam et al., 2014).

Despite extensive research on distribution principles, there is no consensus regarding when each principle is most likely to be used or when each rule is likely to be seen as most fair in a given situation (McLean Parks et al., 1999; Thatcher \& Bagger, 2011). However, there is some evidence that, in organizations that give the most importance to economic considerations and productivity, equity, rather than equality, is the dominant principle (Deutsch, 1975; Hysom \& Fişek, 2011). Nevertheless, many organizations proclaim that they use the equality principle and proactively signal it to potential applicants, e.g. via their corporate website (e.g., Microsoft, 2014) or social media (BMW Group, 2014).

Research on idiosyncratic deals (i-deals) suggests that individual treatment signals a climate of organizational justice (Greenberg et al., 2004; Rousseau et al., 2006). 
When organizations signal that workplace flexibility is given only to high performers, applicants may perceive this as fair because it is distributed in proportion to employees' input. Consequently, they are likely to perceive workplace flexibility as a special perquisite (Gajendran et al., 2015). Also increasing individualization (Twenge, 2010) supports the equity principle. Furthermore, an equity-based distribution addresses employees' urgent need for workplace recognition, signaling that they are recognized for their contribution to company success (Brun \& Dugas, 2008). In contrast, an application of the equality principle could signal that an organization lacks appreciation of its employees as individuals (Lambert, 2000). If workplace flexibility is given to everyone, it is likely that applicants experience this as a signal that it is a relatively normative aspect within the organization, what could diminish the distinctiveness of their flexibility (Gajendran et al., 2015). Equality has also been found to negatively influence the extent to which employees perceive autonomy from workplace flexibility (Gajendran et al., 2015). Hypothesis 3 follows this argumentation.

Hypothesis 3: An equity-based distribution positively moderates the influence of a) temporal flexibility, b) spatial flexibility and c) their combination on perceived organizational attractiveness, as potential applicants perceive an organization that signals its equity-based distribution of workplace flexibility as more attractive than an organization that signals its equalitybased distribution.

Figure 1 graphically summarizes the analysis model.

\section{Figure 1. Analysis model}

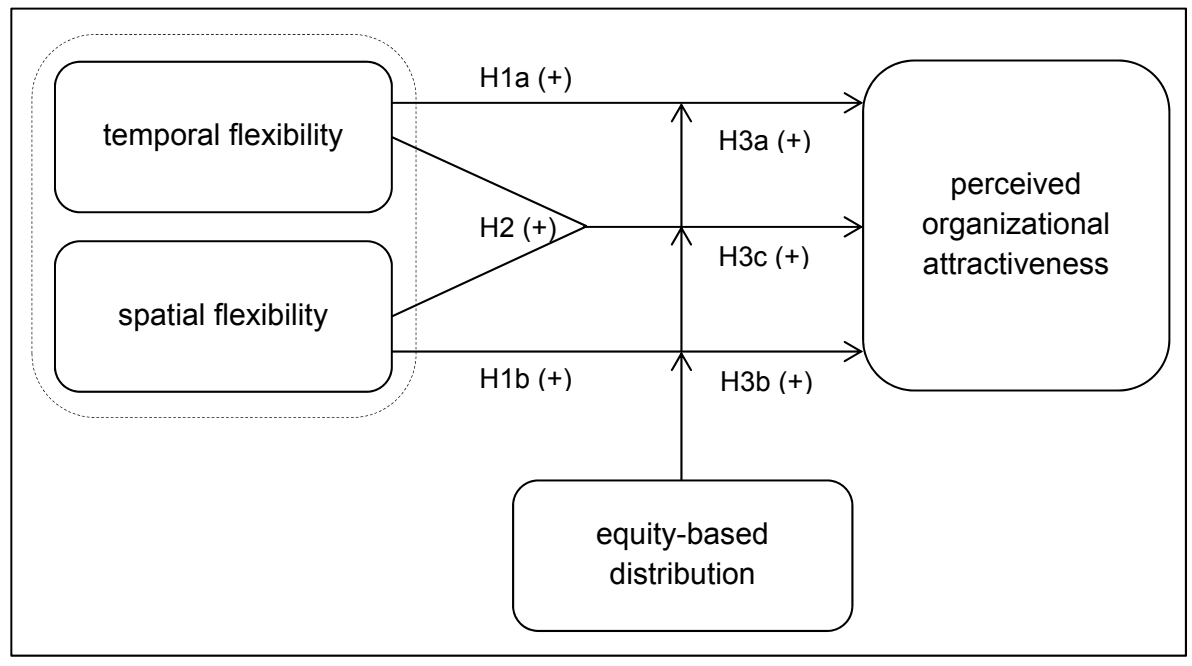




\section{Research Design and Sample}

Overall, there is a lack of experimental research on workplace flexibility that has a high level of internal validity and permits causal inferences (Allen \& Shockley, 2009; Thompson et al., 2015). We seek to overcome this lack by conducting a randomized vignette-based experiment using a $2 \times 2 \times 2$ pretest-posttest design. The vignette-based methodology allowed us to manipulate certain aspects of a written stimulus while controlling for confounding effects that would be not controllable in real-life settings (Evans et al., 2015). The pretest-posttest design has the advantage that the change in subjects' perception of organizational attractiveness can be captured in isolation. Thus, this approach ensures that every participant serves as his or her own control, which increases the statistical tests' power and precision (Morris, 2008). To ensure the success of the design, we conducted two pilot studies. The results of the first pilot study $(\mathrm{N}=30)$ led us to modify the scenarios slightly. The second pilot study $(\mathrm{N}=38)$ revealed no need for further modifications.

The participants were addressed during lectures at four German universities. We made clear that their data would be treated anonymously and for scientific purposes only. The completion of the paper-and-pencil survey took about ten minutes. Similar to their own real-life situation, the respondents were asked to imagine themselves as actual job-seekers (e.g., Stockman et al., 2017) before they were shown a job advertisement from a fictitious German retailer ("MARZEO") for a position as a trainee in the corporate headquarter. Companies in the retail industry are particularly suited to research on organizational attraction, as this industry has an expandable employer attractiveness (Rudolph \& Runco, 2006). This is especially important when using a pretest-posttest design, as the pre-measurement has to be capable for improvement. To enhance external validity, the job advertisement was created based on real job advertisements from established retailers.

The participants were asked to read the job advertisement carefully. Then they rated the organizational attraction, thereby generating the pre-measurement ("baseline"). Subsequently, the participants received information related to the working conditions at MARZEO; temporal flexibility $[1=$ yes; $0=$ no], spatial flexibility $[1=$ yes; $0=$ no] and distribution $[1=$ equity-based; $0=$ equality-based $]$ were manipulated (see Appendix). The participants were randomly assigned to one of the eight experimental conditions. They read the scenario and rated organizational attraction for a second time to generate the post-measurement. The difference between the pre- and post-measurements yielded the isolated inner-subject change $(\Delta)$ in perceived organizational attraction.

Organizational attraction was measured using a five-item scale developed by AimanSmith et al. (2001) to which participants responded with answers ranging from 1 ("strongly disagree") to 7 ("strongly agree"). An example item is "I find this a very attractive company." The internal consistency of the scale was very good (pre-measurement: $\alpha=.92$; post-measurement: $\alpha=.96$ ). 
The present study addresses organizational attraction as perceived by potential applicants. Students are appropriate subjects, as it is very likely that they will become strategically relevant for many organizations (Baum \& Überschaer, 2016). Thus, it is important to gain knowledge on how their perceived organizational attraction is affected. As a main target group of time-consuming and costly recruiting efforts (Aiman-Smith et al., 2001; Sivertzen et al., 2013) they are a widespread study population in research on organizational attraction (e.g., Baum et al., 2016; Stockman et al., 2017). To increase the practical relevance of our sample, we asked 419 business students who were at an advanced stage in their bachelor's program (67\%) or master's program $(33 \%)$ to participate in this study, as they would soon be entering the labor market (e.g., Stockman et al., 2017). We conducted manipulation check items (e.g., "Does the company offer temporal flexibility?"; yes/no) to verify whether participants had read the scenario with sufficient attention and were aware of our manipulations (Stockman et al., 2017), thereby ensuring that the manipulations elicited the desired effect (Evans et al., 2015). In line with other experimental studies (e.g., Barlow et al., 2013; Stockman et al., 2017; Köllner et al., 2018) all respondents who did not answer the questions correctly were removed from the dataset, because it cannot be assumed that the manipulated factor triggered variation in the dependent variable.

Our final sample consisted of 334 students of which 54 percent were female and 46 percent were male. Participants' ages varied between 20 and 36 years $(\mathrm{M}=22.8$ years, $S D=2.68)$. Choosing a relatively homogenous group of students strengthens the research design (Sivertzen et al., 2013; Rode \& Süß, 2015). The participants predominantly $(62 \%)$ indicated that they were job-seekers or planning to be within a year. We conclude that our sample is appropriate for an investigation of potential applicants' perceptions of organizational attraction.

\section{Results}

We conducted a three-way ANOVA on difference scores to test the hypotheses. Alternatively, we conducted an ANCOVA with the pre-measurement as the covariate and the post-measurement as the dependent variable and found comparable results. Although the use of ANCOVA is a common approach for analyzing pretest-posttest designs, baseline differences between groups indicated that it is more appropriate to use ANOVA on difference scores (Smolkowski, 2013).

The inner-subject change $(\Delta)$ overall has a significant $(\mathrm{p}<.001)$ effect on the participants' perceptions of organizational attraction, as their perceptions differ significantly between pre-measurement and post-measurement. Table 1 shows the means and standard deviations for each experimental condition and the difference $(\Delta)$ between pre-measurement $\left(\mu^{1}\right)$ and post-measurement $\left(\mu^{2}\right)$.

The ANOVA reveals a statistically significant main effect of temporal flexibility on organizational attraction $\left(\mathrm{F}[1,326]=121.72 ; \mathrm{p}<.001 ; \omega^{2}=.223\right)$, providing strong 
support for hypothesis $1 \mathrm{a}$. We also found support for hypothesis $1 \mathrm{~b}$, as spatial flexibility has a statistically significant main effect on organizational attraction ( $\mathrm{F}[1$, $\left.326]=73.76 ; \mathrm{p}<.001 ; \omega^{2}=.134\right)$. These results also show that temporal flexibility has a greater effect size than spatial flexibility does, with temporal flexibility having a large effect size and spatial flexibility a medium one (e.g., Field, 2013).

Table 1. Means, standard deviations and difference scores across each condition

\begin{tabular}{|lcccccccc|}
\hline$\underline{\text { Scenario }}$ & $\underline{111}$ & $\underline{110}$ & $\underline{101}$ & $\underline{100}$ & $\underline{011}$ & $\underline{010}$ & $\underline{001}$ & $\underline{000}$ \\
equity-based distribution & yes & yes & yes & yes & no & no & no & no \\
temporal flexibility & yes & yes & no & no & yes & yes & no & no \\
spatial flexibility & yes & no & yes & yes & yes & no & yes & no \\
$\mu^{1}$ organizational attraction & 4.22 & 4.20 & 4.78 & 4.34 & 4.45 & 4.53 & 4.67 & 4.39 \\
$\mu^{2}$ organizational attraction & 5.43 & 4.49 & 4.80 & 3.43 & 5.47 & 4.81 & 4.77 & 3.86 \\
$\Delta$ organizational attraction & 1.20 & .29 & .02 & -.91 & 1.02 & .28 & .10 & -.53 \\
SD $\Delta$ & .86 & .73 & .80 & 1.02 & .81 & .91 & .74 & .88 \\
Totals $(N=334)$ & 47 & 30 & 37 & 40 & 42 & 43 & 46 & 49 \\
\hline
\end{tabular}

Hypothesis 2, which suggests that potential applicants perceive an organization that offers temporal and spatial flexibility as more attractive than an organization that offers only one or the other, finds support. The formation of homogeneous subsets using a Tukey post hoc test confirms significant differences between the scenarios, with zero, one and two dimensions of flexibility (Table 2). Because of the unequal sample sizes, we use the harmonic mean $(M=41.073)$. Subset 2 , which contains the scenarios that offer only one type of flexibility, differs significantly from Subset 3 , which contains the scenarios that offer both types. However, there is no significant interaction between temporal and spatial flexibility, so the combination of the two types of flexibility has additive, rather than synergistic, effects on organizational attraction $\left(\mathrm{F}[1,326]=.09 ; \mathrm{p}=.768 ; \omega^{2}=.000\right)$.

Table 2. Homogeneous subsets

\begin{tabular}{|c|c|c|c|c|c|c|c|}
\hline \multirow[t]{2}{*}{$\underline{\text { scenario }}$} & \multirow{2}{*}{$\begin{array}{c}\begin{array}{c}\text { equity- } \\
\text { distribution }\end{array} \\
\end{array}$} & \multirow{2}{*}{$\frac{\text { temporal }}{\text { flexibility }}$} & \multicolumn{2}{|l|}{ spatial flexi- } & \multicolumn{3}{|c|}{$\underline{\text { subsets }}$} \\
\hline & & & bility & $\underline{N}$ & $\underline{1}$ & $\underline{2}$ & $\underline{3}$ \\
\hline 100 & yes & no & no & 40 & -.91 & & \\
\hline 000 & no & no & no & 49 & -.53 & & \\
\hline 101 & yes & no & yes & 37 & & .02 & \\
\hline 001 & no & no & yes & 46 & & .10 & \\
\hline 010 & no & yes & no & 43 & & .28 & \\
\hline 110 & yes & yes & no & 30 & & .29 & \\
\hline 011 & no & yes & yes & 42 & & & 1.02 \\
\hline 111 & yes & yes & yes & 47 & & & 1.20 \\
\hline
\end{tabular}

Note. Dependent variable: $\Delta$ organizational attraction 
Hypotheses 3a-c, which propose that equity-based distribution moderates the effects of flexibility on organizational attraction, are not supported, as the ANOVA for neither the triple interaction among equity-based distribution (H1c), temporal flexibility and spatial flexibility $\left(\mathrm{F}[1,326]=.14 ; \mathrm{p}=.705 ; \omega^{2}=.000\right)$ nor the interaction between equity-based distribution and spatial flexibility $(\mathrm{H} 1 \mathrm{~b})(\mathrm{F}[1,326]=$ $\left.1.51 ; \mathrm{p}=.220 ; \omega^{2}=.001\right)$ shows statistically significant effects. Only when a relatively high error probability $(\mathrm{p}<.10)$ is assumed, there is a significant interaction between equity-based distribution and temporal flexibility (H1a) with a moderate effect size $\left(\mathrm{F}[1,326]=2.99 ; \mathrm{p}=.084 ; \omega^{2}=.004\right)$.

The overall model explains 38.4 percent of the variance $\left(\mathrm{R}^{2}=.397\right.$; corr. $\left.\mathrm{R}^{2}=.384\right)$. Table 3 provides an overview of the ANOVA.

Table 3. Three-way ANOVA Table

\begin{tabular}{|l|c|c|c|c|c|c|c|}
\hline \multicolumn{1}{|c|}{ Source of Variation } & Type III SS & \multicolumn{1}{c|}{$d f$} & \multicolumn{1}{c|}{ MS } & \multicolumn{1}{c|}{$F$} & \multicolumn{1}{c|}{$p$} & \multicolumn{1}{c|}{$\eta p^{2}$} & $\omega^{2}$ \\
\hline equity-based distribution & .378 & 1 & .378 & .534 & .466 & .002 & .000 \\
\hline temporal flexibility & 86.301 & 1 & 86.301 & 121.718 & .000 & .272 & .223 \\
\hline spatial flexibility & 52.308 & 1 & 52.308 & 73.775 & .000 & .185 & .134 \\
\hline $\begin{array}{l}\text { equity } \times \text { temporal } \\
\text { flexibility }\end{array}$ & 2.123 & 1 & 2.123 & 2.994 & .084 & .009 & .004 \\
\hline equity $\times$ spatial flexibility & 1.068 & 1 & 1.068 & 1.507 & .220 & .005 & .001 \\
\hline $\begin{array}{l}\text { temporal flexibility } \times \\
\text { spatial flexibility }\end{array}$ & .062 & 1 & .062 & .087 & .768 & .000 & .000 \\
\hline $\begin{array}{l}\text { equity } \times \text { temporal flexi- } \\
\text { bility } \times \text { spatial flexibility }\end{array}$ & .102 & 1 & .102 & .144 & .705 & .000 & .000 \\
\hline Error & 231.143 & 326 & .709 & & & & \\
\hline Total & 394.960 & 334 & & & & & \\
\hline Corrected total & 383.152 & 333 & & & & & \\
\hline
\end{tabular}

Note. Dependent variable: $\Delta$ organizational attraction; $\mathrm{R}$-squared $=.397$

(adjusted R-squared $=.384$ )

\section{Conclusions}

\section{Discussion}

The present study provides valuable insights into how temporal flexibility and spatial flexibility affect organizational attraction. Our empirical experiment shows that temporal flexibility has a statistically significant influence on organizational attraction. Potential applicants perceive an organization that offers temporal flexibility as more attractive than an organization that does not. This result is in line with Nadler et al. (2010) but the current study explains a much higher proportion of the variance (Nadler et al., 2010, with $\mathrm{p}=.03$ and $\eta \mathrm{p}^{2}=.03$ ). The current study also supports the findings of Thompson et al. (2015, with $\mathrm{p}<.05$ and prv $=.08)$, who opera- 
tionalize temporal flexibility with the restriction that employees are free to work whenever they want only as long as they get their work done. Our findings reduce the chance that previous results on the positive relationship between temporal flexibility and organizational attraction were due to the studies' particular characteristics.

Our study also shows that spatial flexibility has a significant impact on organizational attraction, as the potential applicants in our experiment perceived an organization that offers spatial flexibility as more attractive than an organization that does not. This result is in line with previous research, but the current study provides significant effects with a larger effect size and, therefore, more explanation of variance (Rau \& Hyland, 2002, with $\mathrm{p}<.05$ and $\beta=.21$; Thompson et al., 2015, with $\mathrm{p}<.05$ and prv =.02). This result could be related to the fact that the few previous studies that examine the impact of spatial flexibility on organizational attraction operationalized spatial flexibility only as the opportunity to work from home. Many studies do not keep pace with the extent to which spatial flexibility has changed (Hislop \& Axtell, 2007). As Barley \& Kunda (2001) state, management studies must use images of organizations that are congruent with the realities of work. With this requirement in mind, our study is the first one that makes no restrictions regarding the location of work. The level of significance and the large effect size in our study suggest that restrictions on the extent of spatial flexibility may diminish the positive effect on organizational attraction.

Another interesting finding of the study is that temporal flexibility has more influence on potential applicants' perceptions of organizational attraction than spatial flexibility does. We show for the first time that even unrestricted spatial flexibility has less influence on organizational attraction than temporal flexibility does. A possible explanation for this result might be related to the boundary theory (Ashforth et al., 2000), which proposes that individuals create and maintain boundaries in order to organize and contextualize their environment. These boundaries are crucial because they signal individuals about when to fulfill work roles and when to fulfill family roles. Without such signals, the boundary between work and family roles becomes permeable, increasing the possibility that work and family will conflict (Kossek et al., 2006). Previous research provides indications that spatial flexibility might be less beneficial than temporal flexibility in terms of reducing or avoiding these conflicts (e.g., Allen \& Shockley, 2009; Allen et al., 2013). Instead of reinforcing the perception of autonomy and self-control, blurred boundaries may result in the opposite (Allen et al., 2013). Another possible explanation for the lower influence of spatial flexibility on organizational attraction is the potential applicants' fear of the professional and social isolation that is sometimes associated with this kind of flexibility (e.g., Cooper \& Kurland, 2002; Collins et al., 2016).

The results of our study also indicate that the combination of temporal and spatial flexibility matters in organizational attraction. Potential applicants perceive an orga- 
nization that offers both temporal and spatial flexibility as the most attractive. The combination of the two kinds of flexibility results in much higher ratings of organizational attraction than does one or the other. However, the combination has additive, rather than synergetic, effects. This result can be explained by assuming that synergies that occur in one's real work life are not apparent to applicants because of their lack of work experience (Thompson et al., 2015). Also, having a closer look at the difference scores across each experimental condition provides valuable insights, as the combination of spatial flexibility with no temporal flexibility results in a relatively low change in perceived organizational attraction. It seems likely that it diminishes the positive influence on employer attraction, if an employer signals inconsistent information about the two flexibility dimensions.

Our experiment does not provide evidence for the moderating role of an equitybased distribution of temporal and spatial flexibility. Our findings suggest that the distribution principle has no significant impact, regardless of whether temporal and spatial flexibility are based on equity or equality. Indeed, the results support the assumption that equity-based distribution enhances the effect of temporal flexibility on the perception of a potential employer's attractiveness, but at a significance level higher than $5 \%$. Because of the research on idiosyncratic deals (Rousseau et al., 2006) and against the background of increasing individualization (Twenge, 2010), this finding was unexpected. However, it can be explained by the central role that distributive justice plays, particularly after a distribution has actually taken place (Ambrose \& Cropanzano, 2003). Before such a distribution, potential applicants have no assurance that the announcement of a distribution rule will be followed by realization of that rule (Porter et al., 2004). Furthermore, our participants had not yet provided their own input to an employer, making them incapable of evaluating an input-output relationship (Bos et al., 2001; Li et al., 2015). In addition, they did not have any reference that would enable them to assess whether they are high performers in comparison to other members of the organization. This also accords with the argumentation of Barsky et al. (2011) that justice judgments are part of an appraisal process, emerging over time through the interplay of experience and emotions. The results may also be influenced by the fact that information regarding the distribution procedures was missed. Within several studies it has been shown that procedural justice explains more variance in judgements of fairness than distributive justice. Therefore, some researchers conclude that fairness judgements may be more strongly affected by procedures than by the actual distribution (Bos et al., 2001). But it is also known that distributive justice and procedural justice are highly correlated (Lind, 2001). As predicted in the fairness heuristics theory, the information that comes first, whether procedural or distributive, exerts a stronger influence on fairness judgments than information that comes second (Bos et al., 2001). Nevertheless, the missing information about distribution procedures might have led to individual assumptions regarding procedural justice. 


\section{Contributions}

The present study contributes to research on workplace flexibility as well as to the recruitment literature by providing valuable insights into how workplace flexibility affects organizational attraction.

First, our study contributes to research by addressing the lack of experimental evidence in the discourse on workplace flexibility (e.g., Allen \& Shockley, 2009; Thompson et al., 2015). A pretest-posttest approach has been used in this field for the first time. This contribution is very important as a majority of conclusions made about workplace flexibility are based on correlational data that only pretend causal relationships (Thompson et al., 2015). This is perilous, because in the existing research parameter estimates are likely to be biased and may yield erroneous findings (Antonakis et al., 2010), resulting in wrong conclusions drawn for practice and research. We overcome this by using a randomized experiment with a pretest-posttest design that allows for the causal conclusion that offering temporal and spatial flexibility has a positive influence on potential applicants' perceptions of organizational attraction. Our experimental approach contributes to the discourse as it can function as a guide for future studies in the field of workplace flexibility.

Second, we address the lack of clear and consistent differentiation between temporal and spatial flexibility in the body of research that focuses on workplace flexibility (e.g., Allen et al., 2013; Gerdenitsch et al., 2015; Kossek \& Thompson, 2016). The findings may help to explain how temporal and spatial flexibility differ in terms of their influence on organizational attraction. In contrast to other studies (e.g., Rau \& Hyland, 2002; Thompson et al., 2015) we provide information about the influence of "anywhere working" on organizational attraction. Based on our findings, we can conclude that temporal flexibility is more important than spatial flexibility even if it is unrestricted - in increasing an employer's attractiveness as perceived by potential applicants. Given the different effect sizes we found, also future investigations on other endogenous variables should make a consistent differentiation between flexibility that is associated with location (spatial flexibility) and flexibility that is associated with time (temporal flexibility). Identifying similarities and differences in patterns of associations helps to clarify the effects of workplace flexibility.

Our differential approach also contributes to signaling theory by addressing the issue of signal consistency (e.g., Gao et al., 2008; Connelly et al., 2011). For instance, providing positive information regarding spatial flexibility together with negative information regarding temporal flexibility results in a low-level inner-subject change in perceived organizational attraction. This indicates that conflicting signals regarding the dimensions of workplace flexibility may unsettle potential applicants. In addition, our findings contribute to the literature on signaling theory as there is little research on negative signals (Connelly et al., 2011). Our findings show that negative signals regarding workplace flexibility minimize recruitment outcomes. Signaling information that applicants will not receive workplace flexibility 
results in significantly lower ratings of organizational attraction compared to an absence of information about workplace flexibility.

Moreover, our study contributes to research on the distribution of workplace flexibility and the discourse on organizational attraction, as it is one of the first that combines these research areas. A recent literature review (Putnam et al., 2014) on workplace flexibility reveals that the tension of equity-based versus equality-based distribution of workplace flexibility is a key issue in the discourse. However, in terms of applicant attraction it does not seem to be that important. At least for potential applicants, the distribution of workplace flexibility has no significant impact, regardless of whether its allocation is based on the principle of equity or that of equality. This is a crucial finding as organizations typically manage this tension through choosing one pole over the other in order to attract potential applicants (Putnam et al., 2014). Our findings suggest that this is not necessary as it does not have a significant impact on the organizational attraction.

\section{Practical Implications}

Our study has several implications for practice. Overall, it indicates that signaling the possibility to receive workplace flexibility can increase applicants' perceptions of organizational attraction. Linking individual cognitions to organizational actions requires the perceptual and interpretive processes of decision-makers (Dutton \& Jackson, 1987). Our study provides an opportunity to sensitize decision-makers on the relationship between signaling the possibility to receive workplace flexibility and organizational attraction.

From a practical perspective, companies that already offer workplace flexibility to their current employees should signal this to potential applicants in order to increase their organizational attraction, a benefit they can realize without significant additional expenditure. Potential applicants perceive both dimensions of flexibility as a positive signal, so they can help to increase employer attractiveness. A company that already offers its employees both temporal and spatial flexibility should clearly highlight that they do so in the recruitment context in order to take advantage of the additive effects of both dimensions. However, the postulated signals should correspond to the reality in the company, as new employees may quickly perceive false impressions. Providing true information is important in the creation and maintenance of a well-functioning employment relationship (Rousseau, 2001) and may prevent from turnover at an early stage.

The finding that temporal flexibility has a stronger influence on organization attraction than spatial flexibility does is also useful for practice, particularly for companies that cannot provide spatial flexibility to their employees because of, for example, production requirements. In this case, the company should highlight at least the offer of temporal flexibility in the recruitment process in order to benefit from this type of flexibility. 


\section{Limitations and Future Research}

Whilst our study has some key strengths such as the use of an experimental approach, it also exhibits several limitations. We hope that these limitations provide inspiration for future research.

Some limitations could be associated with our sample. While students have been the population in numerous studies on organizational attraction (e.g., Baum et al., 2016; Evertz \& Süß, 2017; Stockman et al., 2017), the sample may reduce our findings' generalizability to other groups, such as experienced job-seekers and tenured employees. In order to increase their external validity, future studies could either focus on applicant behavior in field or replicate our experiment with employees who already have experience with workplace flexibility.

Another limitation results from our operationalization of flexibility. In line with the majority of studies in the field of workplace flexibility (Shockley \& Allen, 2010; Kossek \& Thompson, 2016), we treated temporal and spatial flexibility dichotomously. We chose the degrees of flexibility (either no flexibility or unrestricted flexibility) to be in keeping with our study's purpose. Future studies could overcome this limitation by using ordinal-scaled or interval-scaled measures of temporal and spatial flexibility to yield different effects based on different degrees of workplace flexibility.

We have not tested potential mediation processes, the underlying signal-based mechanisms by which causal influences are transmitted. For instance, spatial flexibility could trigger trust (Gajendran et al., 2015) and temporal flexibility instead responsive behavior against employees (Casper \& Buffardi, 2004). Future studies could open this black-box in order to clarify if the different flexibility dimensions trigger different mediators.

In our study information regarding the procedure how workplace flexibility is distributed is missing. For example, there was no information on how the organization evaluates, whether somebody is a high performer that will receive workplace flexibility or not. Also there was no information regarding if future employees are given a voice in the evaluation process. Even if it is very difficult to calibrate several experimental conditions of organizational justice (Lind, 2001), future studies could manipulate the distribution of workplace flexibility as well as the procedures that lead to the distribution, in order to provide a more nuanced picture on the connection between workplace flexibility and organizational justice.

As pointed out by a current literature review (Evertz \& Süß, 2017) future research on organizational attraction might also take an array of individual differences into consideration. Although randomization in our study ensures the comparability of treatment groups with regard to individual differences, it is likely that some individuals are more attracted by workplace flexibility than others. For example, extroverted people who enjoy interactions at work might be less attracted by workplace flexi- 
bility that comes along with greater temporal and spatial distance to co-workers. Also socio-demographic differences could be taken into account. For instance, it is conceivable that family responsibilities could play a major role (Shockley \& Allen, 2010).

In addition, research within another national context could provide valuable contributions. As shown by Baum \& Kabst (2013) some facets of organizational attraction vary across different countries. Especially work-life comfort seems to be very prone to cross-national differences (Baum \& Kabst, 2013). Thus, it is likely that attraction to workplace flexibility, as tool to help individuals manage work and family domains (Allen et al., 2013), is not consistent across different countries.

\section{References}

Adams, S. J. (1969). Inequity in social exchange. In: L. Berkowitz (ed.), Advances in Experimental Social Psychology (pp. 267-299). New York: Academic Press.

Aiman-Smith, L., Bauer, T. N., \& Cable, D. M. (2001). Are You Attracted? Do You Intend to Pursue? A Recruiting Policy-Capturing Study. Journal of Business and Psychology, 16(2), 219-237.

Allen, T. D., Golden, T. D., \& Shockley, K. M. (2015). How Effective Is Telecommuting? Assessing the Status of Our Scientific Findings. Psychological Science in the Public Interest, 16(2), 4068.

Allen, T. D., Johnson, R. C., Kiburz, K. M., \& Shockley, K. M. (2013). Work-Family Conflict and Flexible Work Arrangements: Deconstructing Flexibility. Personnel Psychology, 66(2), 345376.

Allen, T. D., \& Shockley, K. M. (2009). Flexible Work Arrangements: Help or Hype? In: D. R. Crane \& E. J. Hill (eds.), Handbook of Families and Work: Interdisciplinary Perspectives (pp. 265-284). Lanham: University Press of America.

Ambrose, M. L., \& Cropanzano, R. (2003). A longitudinal analysis of organizational fairness: An examination of reactions to tenure and promotion decisions. Journal of Applied Psychology, 88(2), 266-275.

Antonakis, J., Bendahan, S., Jacquart, P., \& Lalive, R. (2010). On making causal claims: A review and recommendations. The Leadership Quarterly, 21(6), 1086-1120.

Ashforth, B. E., Kreiner, G. E., \& Fugate, M. (2000). All in a Day's Work: Boundaries and Micro Role Transitions. The Academy of Management Review, 25(3), 472-491.

Barley, S. R., \& Kunda, G. (2001). Bringing Work Back In. Organization Science, 12(1), 76-95.

Barlow, J. B., Warkentin, M., Ormond, D., \& Dennis, A. R. (2013). Don't make excuses! Discouraging neutralization to reduce IT policy violation. Computers \& Security, 39, 145-159.

Barsky, A., Kaplan, S. A., \& Beal, D. J. (2011). Just Feelings? The Role of Affect in the Formation of Organizational Fairness Judgments. Journal of Management, 37(1), 248-279.

Baum, M., \& Kabst, R. (2013). How to attract applicants in the Atlantic versus the Asia-Pacific region? A cross-national analysis on China, India, Germany, and Hungary. Journal of World Business, 48(2), 175-185. 
Baum, M., Sterzing, A., \& Alaca, N. (2016). Reactions towards diversity recruitment and the moderating influence of the recruiting firms' country-of-origin. Journal of Business Research, 69(10), 4140-4149.

Baum, M., \& Überschaer, A. (2016). When do employer awards pay off and when do they not? The impact of award familiarity on applicants' job pursuit intentions and the moderating role of corporate brand awareness. The International Journal of Human Resource Management, 4, 123.

Beechler, S., \& Woodward, I. C. (2009). The global "war for talent". Journal of International Management, 15(3), 273-285.

Beers, T. M. (2000). Flexible schedules and shift work: replacing the '9-to-5' workday? Monthly Labor Review, 123(6), 33-40.

Berthon, P., Ewing, M., \& Hah, L. L. (2005). Captivating company: dimensions of attractiveness in employer branding. International Journal of Advertising, 24(2), 151-172.

Blount, Y. (2015). Pondering the Fault Lines of Anywhere Working (Telework, Telecommuting): A Literature Review. Foundations and Trends in Information Systems, 1(3), 163-276.

BMW Group (2014). BMW Karriere: Betriebsvereinbarung zur Mobilarbeit. Retrieved 27.4.2018, from https://www.facebook.com/bmwkarriere/posts/10203488332517198.

Bos, K., Lind, E. A., \& Wilke, H. A. M. (2001). The Psychology of Procedural and Distributive Justice Viewed From the Perspective of Fairness Heuristic Theory. In: R. S. Cropanzano (ed.), Justice in the Workplace: From Theory to Practice (2nd ed., pp. 49-66). Mahwah: Psychology Press.

Boswell, W. R., Roehling, M. V., LePine, M. A., \& Moynihan, L. M. (2003). Individual jobchoice decisions and the impact of job attributes and recruitment practices: A longitudinal field study. Human Resource Management, 42(1), 23-37.

Brummelhuis, L. L. t., Bakker, A. B., Hetland, J., \& Keulemans, L. (2012). Do new ways of working foster work engagement? Psicothema, 24(1), 113-120.

Brun, J.-P., \& Dugas, N. (2008). An analysis of employee recognition: Perspectives on human resources practices. The International Journal of Human Resource Management, 19(4), 716-730.

Bundesministerium für Arbeit und Soziales (2015). Zeit- und ortsflexibles Arbeiten in Betrieben: Sammlung betrieblicher Gestaltungsbeispiele. Rostock: Publikationsversand der Bundesregierung.

Bundesministerium für Arbeit und Soziales (2016). Orts- und zeitflexibles Arbeiten gestalten: Empfehlungen der Plattform "Digitale Arbeitswelt". Rostock: Publikationsversand der Bundesregierung.

Bundesministerium für Arbeit und Soziales (2017). Weissbuch Arbeiten 4.O. Arbeit weiter denken. Rostock: Publikationsversand der Bundesregierung.

Cable, D. M., \& Turban, D. B. (2001). Establishing the dimensions, sources and value of job seekers' employer knowledge during recruitment. In: M. R. Buckley, J. R. B. Halbesleben, \& A. R. Wheeler (eds.), Research in Personnel and Human Resources Management (pp. 115-163). New York: Emerald Publishing.

Casper, W. J., \& Buffardi, L. C. (2004). Work-life benefits and job pursuit intentions: The role of anticipated organizational support. Journal of Vocational Behavior, 65(3), 391-410.

Clark, A. E. (2005). Your Money or Your Life: Changing Job Quality in OECD Countries. British Journal of Industrial Relations, 43(3), 377-400. 
Collins, A. M., Hislop, D., \& Cartwright, S. (2016). Social support in the workplace between teleworkers, office-based colleagues and supervisors. New Technology, Work and Employment, 31(2), 161-175.

Connelly, B. L., Certo, S. T., Ireland, R. D., \& Reutzel, C. R. (2011). Signaling Theory: A Review and Assessment. Journal of Management, 37(1), 39-67.

Cooper, C. D., \& Kurland, N. B. (2002). Telecommuting, professional isolation, and employee development in public and private organizations. Journal of Organizational Behavior, 23(4), 511-532.

Demerouti, E., Derks, D., Brummelhuis, L. L. t., \& Bakker, A. B. (2014). New Ways of Working: Impact on Working Conditions, Work-Family Balance, and Well-Being. In: C. Korunka \& P. Hoonakker (eds.), The Impact of ICT on Quality of Working Life (pp. 123-141). Dordrecht: Springer.

Deutsch, M. (1975). Equity, Equality, and Need: What Determines Which Value Will Be Used as the Basis of Distributive. Journal of Social Issues, 31(3), 137-149.

Diaz, I., Chiaburu, D. S., Zimmerman, R. D., \& Boswell, W. R. (2012). Communication technology: Pros and cons of constant connection to work. Journal of Vocational Behavior, 80(2), 500-508.

Dutton, J. E., \& Jackson, S. E. (1987). Linking individual organisational perspective. Academy of Management Review, 12(1), 76-90.

Eisenberger, R., Fasolo, P., \& Davis-LaMastro, V. (1990). Perceived organizational support and employee diligence, commitment, and innovation. Journal of Applied Psychology, 75(1), 51-59.

Evans, M. G. (1973). Notes on the impact of Flextime in a large insurance company: I. Reactions of non-supervisory employees. Occupational Psychology, 47(3-4), 237-240.

Evans, S. C., Roberts, M. C., Keeley, J. W., Blossom, J. B., Amaro, C. M., Garcia, A. M.,... Reed, G. M. (2015). Vignette methodologies for studying clinicians' decision-making: Validity, utility, and application in ICD-11 field studies. International Journal of Clinical and Health Psychology, 15(2), 160-170.

Evertz, L., \& Süß, S. (2017). The importance of individual differences for applicant attraction: A literature review and avenues for future research. Management Review Quarterly, 67(3), 141174.

Field, A. (2013). Discovering Statistics Using IBM SPSS Statistics. Thousand Oaks: Sage.

Gajendran, R. S., Harrison, D. A., \& Delaney-Klinger, K. (2015). Are Telecommuters Remotely Good Citizens? Unpacking Telecommuting's Effects on Performance Via I-Deals and Job Resources. Personnel Psychology, 68(2), 353-393.

Gao, H., Darroch, J., Mather, D., \& MacGregor, A. (2008). Signaling Corporate Strategy in IPO Communication: A Study of Biotechnology IPOs on the NASDAQ. Journal of Business Communication, 45(1), 3-30.

Gärtner, M., Garten, T., \& Huesmann, M. (2016). Flexible Arbeitsmodelle für Führungskräfte. Zum Stand der Forschung. Zeitschrift für Arbeitswissenschaft, 70(4), 220-230.

Gerdenitsch, C., Kubicek, B., \& Korunka, C. (2015). Control in Flexible Working Arrangements: When Freedom Becomes Duty. Journal of Personnel Psychology, 14(2), 61-69. 
Greenberg, J., Roberge, M.-É., Ho, V. T., \& Rousseau, D. M. (2004). Fairness in idiosyncratic work arrangements: Justice as an i-deal. In: M. R. Buckley, J. R. B. Halbesleben, \& A. R. Wheeler (eds.), Research in Personnel and Human Resources Management. New York: Emerald Publishing.

Guest, D. E., \& Rodrigues, R. (2015). Career control. In: A. de Vos \& B. van der Heijden (eds.), Handbook of Research on Sustainable Careers (pp. 205-222). Cheltenham.

Handley, K., McGrath-Champ, S., \& Leung, P. (2017). A New Way of Working: Flexibility and Work-Life Balance in the Accounting Profession in Australia. In: Information Resources Management Association (ed.), Remote Work and Collaboration: Breakthroughs in Research and Practice (pp. 243-265). Hershey: IGI Global.

Highhouse, S., Stierwalt, S. L., Bachiochi, P., Elder Allison E., \& Fisher Gwenith (1999). Effects of advertised human resource management pratices on attraction of African American applicants. Personnel Psychology, 52(2), 425-442.

Hill, E. J., Erickson, J. J., Holmes, E. K., \& Ferris, M. (2010). Workplace flexibility, work hours, and work-life conflict: finding an extra day or two. Journal of Family Psychology, 24(3), 349358.

Hill, J. E., Grzywacz, J. G., Allen, S., Blanchard, V. L., Matz-Costa, C., Shulkin, S., \& Pitt-Catsouphes, M. (2008). Defining and conceptualizing workplace flexibility. Community, Work \& Family, 11(2), 149-163.

Hislop, D., \& Axtell, C. (2007). The neglect of spatial mobility in contemporary studies of work: the case of telework. New Technology, Work and Employment, 22(1), 34-51.

Hornung, S., Rousseau, D. M., \& Glaser, J. (2008). Creating flexible work arrangements through idiosyncratic deals. The Journal of Applied Psychology, 93(3), 655-664.

Hysom, S. J., \& Fişek, M. H. (2011). Situational determinants of reward allocation: The equityequality equilibrium model. Social Science Research, 40(4), 1263-1285.

Jones, D. A., Willness, C. R., \& Madey, S. (2014). Why Are Job Seekers Attracted by Corporate Social Performance? Experimental and Field Tests of Three Signal-Based Mechanisms. Academy of Management Journal, 57(2), 383-404.

Kabanoff, B. (1991). Equity, Equality, Power, and Conflict. The Academy of Management Review, 16(2), 416.

Karasek, R. A. (1979). Job Demands, Job Decision Latitude, and Mental Strain: Implications for Job Redesign. Administrative Science Quarterly, 24(2), 285-308.

Köllner, B., Ruhle, S., \& Süß, S. (2018). The moderating role of message content in the formation of employee voice. German Journal of Human Resource Management: Zeitschrift für Personalforschung, 6(24), 239700221879185.

Kossek, E. E., Hammer, L. B., Thompson, R. J., \& Burke Buxbaum, L. (2014). Leveraging Workplace Flexibility for Engagement and Productivity. Retrieved 16.11.2016, from https://w ww.shrm.org/about/foundation/products/Documents/9-14\%20Work-Flex\%20EPG-FINAL.p df.

Kossek, E. E., \& Thompson, R. J. (2016). Workplace Flexibility: Integrating Employer and Employee Perspectives to Close the Research-Practice Implementation Gap. In: T. D. Allen \& L. T. Eby (eds.), The Oxford Handbook of Work and Family (pp. 255-270). New York: Oxford Unicersity Press. 
Kossek, E. E., Lautsch, B. A., \& Eaton, S. C. (2006). Telecommuting, control, and boundary management: Correlates of policy use and practice, job control, and work-family effectiveness. Journal of Vocational Behavior, 68(2), 347-367.

Lambert, S. J. (2000). Added Benefits: The Link between Work-Life Benefits and Organizational Citizenship Behavior. The Academy of Management Journal, 43(5), 801-815.

Li, A., Cropanzano, R. S., \& Agustin, M. (2015). Fairness at the Unit Level: Justice Climate, Justice Climate Strength, and Peer Justice. In: R. S. Cropanzano \& M. L. Ambrose (eds.), The Oxford Handbook of Justice in the Workplace (pp. 137-164). New York: Oxford Library of Psychology.

Lievens, F., Decaesteker, C., \& Coetsier, P. (2001). Organizational Attractiveness for Prospective Applicants: A Person-Organisation Fit Perspective. Applied Psychology: An International Review, 50(1), 30-51.

Lind, E. A. (2001). Fairness heuristic theory: Justice judgments as pivotal cognitions in organizational relations. In: J. Greenberg \& R. S. Cropanzano (eds.), Advances in Organizational Justice (pp. 56-88). Stanford: Stanford University Press.

Masuda, A. D., Poelmans, S. A., Allen, T. D., Spector, P. E., Lapierre, L. M., Cooper, C. L.,... Moreno-Velazquez, I. (2012). Flexible Work Arrangements Availability and their Relationship with Work-to-Family Conflict, Job Satisfaction, and Turnover Intentions: A Comparison of Three Country Clusters. Applied Psychology, 61(1), 1-29.

McLean Parks, J., Conlon, D. E., Ang, S., \& Bontempo, R. (1999). The Manager Giveth, the Manager Taketh Away: Variation in Distribution/Recovery Rules Due to Resource Type and Cultural Orientation. Journal of Management, 25(5), 723-757.

Meindl, J. R. (1989). Managing to Be Fair: An Exploration of Values, Motives, and Leadership. Administrative Science Quarterly, 34(2), 252-276.

Messenger, J. C., \& Gschwind, L. (2016). Three generations of Telework: New ICTs and the (R)evolution from Home Office to Virtual Office. New Technology, Work and Employment, 31(3), 195-208.

Microsoft (2014). Microsoft Deutschland führt Vertrauensarbeitsort ein. Retrieved 8.9.2017, from https://news.microsoft.com/de-de/microsoft-deutschland-fhrt-vertrauensarbeitsort-ein/\#s m.000xkxexk16m8esqyvd29anipuiyr\#D0QuV0Dqd0XDh4de.97.

Ministerie van Sociale Zaken en Werkgelegenheid (2016). Wet flexibel werken. Retrieved 5.9.2017, from http://wetten.overheid.nl/BWBR0011173/2016-01-01.

Morris, S. B. (2008). Estimating Effect Sizes From Pretest-Posttest-Control Group Designs. Organizational Research Methods, 11(2), 364-386.

Nadler, J. T., Cundiff, N. L., Lowery, M. R., \& Jackson, S. (2010). Perceptions of organizational attractiveness. Management Research Review, 33(9), 865-876.

Nansen, B., Arnold, M., Gibbs, M., \& Davis, H. (2010). Time, space and technology in the working-home: an unsettled nexus. New Technology, Work and Employment, 25(2), 136-153.

Nilles, J. M. (1975). Telecommunications and Organizational Decentralization. IEEE Transactions on Communications, 23(10), 1142-1147.

Parent-Thirion, A., Biletta, I., Cabrita, J., Vargas, O., Vermeylen, G., Wilczynska, A., \& Wilkens, M. (2016). 6th European Working Survey: Overview Report. Dublin: Eurofound.

Perry-Smith, J. E., \& Blum, T. C. (2000). Work-Family Human Resource Bundles and Perceived Organizational Performance. The Academy of Management Journal, 43(6), 1107-1117. 
Pfeffer, J. (2001). Fighting the war for talent is hazardous to your organization's health. Organizational Dynamics, 29(4), 248-259.

Porter, C. O., Conlon, D. E., \& Barber, A. E. (2004). The dynamics of salary negotiations: Effects on applicants' justice perceptions and recruitment decisions. The International Journal of Conflict Management, 15(3), 273-303.

Possenriede, D., \& Plantenga, J. (2014). Temporal and Locational Flexibility of Work, WorkingTime Fit, and Job Satisfaction. IZA DP, (8436), 1-32.

Putnam, L. L., Myers, K. K., \& Gailliard, B. M. (2014). Examining the tensions in workplace flexibility and exploring options for new directions. Human Relations, 67(4), 413-440.

Rau, B. L., \& Hyland, M. M. (2002). Role Conflict and Flexible Work Arrangements: The Effects on Applicant Attraction. Personnel Psychology, 55(1), 111-136.

Rode, H., \& Süß, S. (2015). Der Einfluss unternehmensinterner Social Media auf die Arbeitgeberattraktivität: Eine szenariobasierte Experimentalstudie. Die Betriebswirtschaft, 75(6), 351367.

Rousseau, D. M. (2001). Schema, promise and mutuality: The building blocks of the psychological contract. Journal of Occupational and Organizational Psychology, 74(4), 511-541.

Rousseau, D. M., Ho, V. T., \& Greenberg, J. (2006). I-Deals: Idiosyncratic Terms in Employment Relationships. The Academy of Management Review, 31(4), 977-994.

Rudolph, T., \& Runco, M. (2006). Das Image von Handelsunternehmen bei Hochschulabsolventen. Retrieved 3.8.2017, from https://www.alexandria.unisg.ch/32575/1/RudolphRunco_D as_Image_von_Handelsunternehmen.pdf.

Ryan, R. M., \& Deci, E. L. (2000). Self-determination theory and the facilitation of intrinsic motivation, social development, and well-being. American Psychologist, 55(1), 68-78.

Shockley, K. M., \& Allen, T. D. (2010). Investigating the missing link in flexible work arrangement utilization: An individual difference perspective. Journal of Vocational Behavior, 76(1), 131-142.

Sivertzen, A.-M., Nilsen, E. R., \& Olafsen, A. H. (2013). Employer branding: Employer attractiveness and the use of social media. Journal of Product \& Brand Management, 22(7), 473-483.

Smolkowski, K. (2013). Gain Score Analysis. Retrieved 10.9.2017, from http://homes.ori.org/kei ths/Tips/Stats_GainScores.html.

Spence, M. (1973). Job Market Signaling. The Quarterly Journal of Economics, 87(3), 355-374.

Stockman, S., van Hoye, G., \& Carpentier, M. (2017). The Dark Side of Employee Referral Bonus Programs: Potential Applicants' Awareness of a Referral Bonus and Perceptions of Organisational Attractiveness. Applied Psychology, 66(4), 599-627.

Swanberg, J. E. (2005). A Question of Justice: Disparities in Employees' Access to Flexible Schedule Arrangements. Journal of Family Issues, 26(6), 866-895.

Thatcher, S. M. B., \& Bagger, J. (2011). Working in Pajamas: Telecommuting, Unfairness Sources, and Unfairness Perceptions. Negotiation and Conflict Management Research, 4(3), 248 276.

The Stationery Office (2014). Terms and Conditions of Employment: The Flexible Working Regulations. Retrieved 9.8.2017, from http://www.legislation.gov.uk/uksi/2014/1398/pdfs/uksi_2 0141398_en.pdf. 
Thompson, R. J., Payne, S. C., \& Taylor, A. B. (2015). Applicant attraction to flexible work arrangements: Separating the influence of flextime and flexplace. Journal of Occupational and Organizational Psychology, 88(4), 726-749.

Turban, D. B. (2001). Organizational Attractiveness as an Employer on College Campuses: An Examination of the Applicant Population. Journal of Vocational Behavior, 58(2), 293-312.

Twenge, J. M. (2010). A Review of the Empirical Evidence on Generational Differences in Work Attitudes. Journal of Business and Psychology, 25(2), 201-210.

Winiger, R. (2011). Praxishandbuch flexible Arbeitszeitmodelle. Zürich: Praxikum.

\section{Appendix}

\section{Table A1. Overview of the manipulations}

\begin{tabular}{|c|c|c|c|}
\hline \multicolumn{4}{|c|}{ Distribution [1 = equity-based; 0 = equality-based] } \\
\hline 1) & We offer high-performing employees... & 2) & We offer all employees... \\
\hline \multicolumn{4}{|c|}{ Temporal flexibility $[1=$ yes $/ 2=$ no] } \\
\hline 1) & an individually selectable working time & 2) & $\begin{array}{l}\text { a fixed working time, based on our busi- } \\
\text { ness hours }\end{array}$ \\
\hline \multicolumn{4}{|c|}{ Spatial flexibility $[1=$ yes $/ 2=$ no] } \\
\hline 1) & an individually selectab & 2) & a modern office as a fixed place of work \\
\hline
\end{tabular}

Note. Translated from German to English 